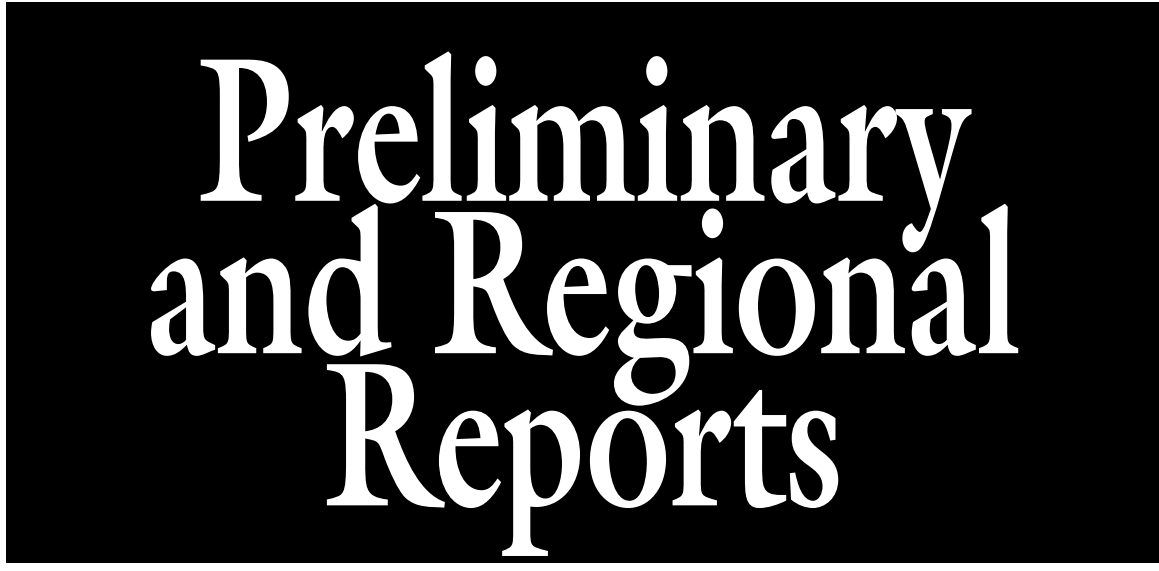

\title{
Assessment of the V45 Blueberry Harvester on Rabbiteye Blueberry and Southern Highbush Blueberry Pruned to V-Shaped Canopy
}

\author{
Fumiomi Takeda ${ }^{1,5,10}$, Gerard Krewer ${ }^{2,6}$, Elvin L. Andrews ${ }^{3,7}$, \\ Benjamin Mullinix, Jr. ${ }^{4,8}$, and Donald L. Peterson ${ }^{1,9}$
}

ADDITIONAL INDEX WORDS. Vaccinium, mechanical harvest, fruit, brusing, quality

SuMMARY. Mechanical harvesting systems for processed blueberries (Vaccinium spp.) are available. However, low harvest efficiency and high fruit damage have limited the use of mechanical harvesters for picking blueberries for fresh market to specific cultivars under good weather conditions. New harvesting technology for fresh-market blueberries is needed. The V45 harvester was developed by the U.S. Department of Agriculture in 1994 to harvest fresh-market-quality northern highbush ( $V$. corymbosum) blueberries in Michigan. The current study was performed in Georgia to evaluate the V45 harvester on specially pruned rabbiteye blueberry [ $V$. virgatum (syn. $V$. ashei)] and southern highbush blueberry ( $V$. darrowi $\times V$. corymbosum) and included analysis of harvest efficiency and fruit quality (percent blue fruit, percent bloom, percent split skin, and internal bruise damage). Six-year-old, 6- to 8-ft-tall 'Brightwell' and 'Powderblue' rabbiteye blueberry plants were winter pruned to remove vertically growing and overarching canes in the center of the bush in Jan. 2004 and Feb. 2005 respectively. Three-year-old, 3- to 5-ft-tall 'FL 86-19' and 'Star' southern highbush blueberry plants were similarly pruned in summer (June 2004) or in winter (Feb. 2005). Pruning removed an estimated $30 \%$ to $50 \%$ of the canopy and opened the middle, resulting in $\mathrm{V}$-shaped plants in both rabbiteye and southern highbush blueberries. Yield of winter-pruned 'Brightwell' rabbiteye blueberry was lower compared with unpruned plants during both years, but winter-pruned 'Powderblue' rabbiteye blueberry plants produced as much as unpruned plants in 2005. In 'FL 86-19' southern highbush blueberry, plants that were summer pruned in June 2004 produced as much as unpruned plants in 2005 , but plants that were winter pruned in Feb. 2005 had lower yields than unpruned plants in 2005. The V45 harvester caused little cane damage on pruned blueberry plants. In rabbiteye blueberries, internal fruit damage and skin splitting was less in V45-harvested fruit than in fruit harvested by a sway harvester and nearly that of hand-harvested fruit. However, in 'FL 86-19' southern highbush blueberry, the V45 harvester detached a lower percentage of blue fruit and excessive amounts of immature and stemmed fruit. These findings suggest that the V45 harvester has the potential to harvest some rabbiteye blueberry cultivars mechanically with fruit quality approaching that of hand-harvested fruit.

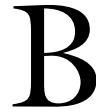
lueberry production in the southern United States (Alabama, Florida, Georgia, Mississippi, North Carolina, South
Carolina, and Tennessee) has expanded to more than 18,750 acres and now makes up $29 \%$ of the planted acreage of rabbiteye and highbush blueberries in the country (Strik and Yarborough, 2005). Specifically, three types of blueberries are produced in the region. Northern highbush blueberry and southern highbush blueberry $(\approx 6750$ acres $)$ are predominantly for the fresh market and, with a few exceptions, are exclusively hand harvested if destined for fresh market (Strik and Yarborough, 2005). In southern Georgia, southern highbush blueberry cultivars ripen in late April and early May. Rabbiteye blueberries $(\approx 12,000$ acres $)$, in contrast, are often machine harvested for the fresh and processing markets in June and July, but quality and shelf life is much less than hand-harvested fruit (Fonsah et al., 2005; Krewer and Nesmith, 2002; Strik and Yarborough, 2005).

Harvesting of highbush blueberries is labor intensive and requires as many as $520 \mathrm{~h}$ of labor per acre (Brown et al., 1983). Hand harvesting costs $\$ 0.50$ to $0.70 / \mathrm{lb}$ for southern highbush blueberries and $\$ 0.39$ to $0.50 / \mathrm{lb}$ for rabbiteye blueberries (Safley et al., 2005). The mechanical harvesting cost for rabbiteye blueberries destined for the fresh and processed markets is about $\$ 0.12 / \mathrm{lb}$, but sorting costs are higher with machine-harvested fruit. In Georgia, hand-harvest labor costs are projected to increase whereas fruit prices are expected to decline as southern highbush blueberry production expands in the southeastern United States and in California (Fonsah et al., 2004). To reduce labor requirements and the cost of harvesting fruit destined for processing, powered pruning and hedging equipment and mechanical harvesting systems have been developed [e.g., Advanced Blueberry Concepts, Holland, MI; Blueberry Equipment Inc. (BEI), South Haven, $\mathrm{MI}$; OXBO (Korvan) International Corp., Lynden, WA; Littau Harvester, Stayton, OR; and Joonas International, Joensuu, Finland]. Over-the-row mechanical harvesters use horizontal tines or rods to shake the fruiting canes, in either horizontal or vertical directions, to detach the ripe fruit. Detached fruit fall to the catching pans (fish scales) and conveyors near the ground. These commercial harvesters were designed in several different ways and are known as rotary shakers, slappers, and sway shakers (Peterson and Brown, 1996). The 
over-the-row harvesters have cut harvest labor to 10 worker-h/acre for blueberries used in processing (Gough, 1994; Mainland, 1993). Mature southern highbush blueberries are commonly machine pruned (topped) with mechanical hedging equipment soon after harvest to promote new shoot growth and to control height followed by winter cane renewal pruning, if needed (Fonsah et al., 2004). Mature rabbiteye blueberries are often moderately machine hedged in some years to restrict plant height and width to 8 and $5 \mathrm{ft}$ respectively to facilitate machine harvesting, or are severely cut back to reduce plant height during a renovation phase (Fonsah et al., 2005). Many rabbiteye blueberry growers practice only limited cane renewal pruning (G. Krewer, pers. obs.), because rabbiteye blueberries typically produce massive canes that are difficult to prune and dispose of. Also, rabbiteye blueberries have lower flower density and have fewer problems with overcropping than southern highbush blueberries (Fonsah et al., 2005).

More than 10 years ago, the U.S. Department of Agriculture developed an experimental blueberry harvester with $45^{\circ}$-angled, spiked-drum shakers, a cane dividing and positioning system, and cushioned catching surfaces (Brown et al., 1996; Peterson and Brown, 1996; Peterson et al.,

We thank Scott Wolford (agricultural engineering technician with USDA, Kearneysville, WV) for operating the V45 blueberry harvester and providing excellent assistance; Wiley Hinson, Adair Peterson, James Chambers, and Jerry Vanerwegen in Homerville, GA, for their interest and cooperation in the conduct of this work; BEI Inc., South Haven, MI, for providing replacement parts for the V45 harvester; and David Trinka and Michigan Blueberry Growers Association's MBG Marketing, Grand Junction, MI, for providing financial assistance for the project.

${ }^{1}$ USDA-ARS, Appalachian Fruit Research Station, 2217 Wiltshire Road, Kearneysville, WV 25430

${ }^{2}$ University of Georgia, Department of Horticulture, Tifton Campus, P.O. Box 748, Tifton, GA 31793

${ }^{3}$ University of Georgia Cooperative Extension Service, 100 Main Street, Courthouse Suite 10, Lakeland, GA 31635

${ }^{4}$ University of Georgia, College of Agricultural and Environmental Sciences, Tifton, Campus, P.O. Box 748, Tifton, GA

${ }^{5}$ Research Horticulturist.

${ }^{6}$ Professor of Horticulture.

${ }^{7}$ Lanier-Clinch County Extension Coordinator.

${ }^{8}$ Agricultural Research Statistician.

${ }^{9}$ Agricultural Engineer (retired).

${ }^{10}$ Corresponding author. E-mail: fumi.takeda@ars. usda.gov.
1997). The cane dividing system bent the canes away from the crown and over onto the elevated catching surface, which greatly reduced the distance of fruit drops and the amount of fruit dropping down in the crown where fish scales are absent (Peterson et al., 1997). The results of machine harvesting well-pruned northern highbush cultivars Bluecrop and Elliott showed that the V45 harvester was as effective and selective as the commercial BEI harvester (Peterson and Brown, 1996; Peterson et al., 1997). Also, the 'Bluecrop' and 'Elliott' fruit detached by the V45 harvester had internal quality and firmness that was better than that of berries harvested by the commercial rotary harvester and as good as commercial hand-harvested fruit (Peterson et al., 1997). The cooperating grower (Degrandchamp's Blueberry Farm, South Haven, MI) shipped a full pallet of V45-harvested fruit to Europe. Another pallet was placed in controlled-atmosphere storage for 6 weeks because the fruit would receive a significantly better price later in the season (Peterson et al., 1997). These mechanical harvesting studies by Brown et al. (1996), Peterson and Brown (1996), and Peterson et al. (1997) were performed on 'Bluecrop' and 'Elliott' plants that had been annually pruned, which produced many small or moderately sized flexible canes. 'Bluecrop' has a spreading growth habit (Gough, 1994). With this variety, the V45 harvester caused little damage to canes, therefore pruning studies to accommodate the harvester better were not considered.

Based on the promising work on northern highbush blueberry, a blueberry grower in Homerville, GA, purchased a V45 blueberry harvester to machine harvest rabbiteye blueberries and southern highbush blueberries. However, the V45 harvester caused severe limb breakage on the rabbiteye blueberry and even pulled the southern highbush blueberry plants out of the ground because the blueberry plants in Georgia were only minimally pruned (J. Vanerwegen, pers. comm.). Apparently the prow and cane positioning system on the V45 was not adequate in dividing the large, stiff, upright canes and caused severe damage. We hypothesized that if upright canes growing in the center were cut out, it would then be possible to machine harvest rabbiteye and southern highbush blueberries with the V45 harvester. Our studies were conducted in 2004 and 2005 to determine the performance of the V45 blueberry harvester on specially pruned rabbiteye and southern highbush blueberries. The objective was to evaluate the effects of summer and winter pruning of southern highbush blueberries and winter pruning of rabbiteye blueberries on yield and harvestability with the V45 blueberry harvester.

\section{Materials and methods}

Pruning of rabbiteye and SOUTHERN HIGHBUSH BLUEBERRIES. All of our work on rabbiteye blueberries was performed on Wiley Hinson Farm in Homerville, GA. A row of 5-year-old (6 to $8 \mathrm{ft}$ tall) 'Brightwell' rabbiteye blueberry plants was winter pruned in Jan. 2004. In Feb. 2005 , an adjacent row of 'Brightwell' plants and 6-year-old ( $6 \mathrm{ft}$ tall) 'Powderblue' rabbiteye blueberry plants were pruned. The initial winter pruning of the 'Brightwell' and 'Powderblue' plants consisted of cutting out two to four large ( $>1.5$ inch in diameter), stiff canes that were growing vertically, down the row or overarching in the center to open the middle. In Feb. 2005, the 'Brightwell' plants that were pruned in Jan. 2004 were lightly pruned to remove 1 -year-old upright canes in the center of the bush. The pruning treatment created a "V" shaped opening that was wide enough for workers to step

\begin{tabular}{lllc}
\hline $\begin{array}{l}\text { Units } \\
\text { To convert U.S. to SI, } \\
\text { multiply by }\end{array}$ & U.S. unit & SI unit & $\begin{array}{l}\text { To convert SI to U.S., } \\
\text { multiply by }\end{array}$ \\
\hline 0.4047 & $\mathrm{acre}(\mathrm{s})$ & $\mathrm{ha}$ & 2.4711 \\
0.3048 & $\mathrm{ft}$ & $\mathrm{m}$ & 3.2808 \\
0.0929 & $\mathrm{ft}^{2}$ & $\mathrm{~m}^{2}$ & 10.7639 \\
3.7854 & $\mathrm{gal}$ & $\mathrm{L}$ & 0.2642 \\
6.4516 & inch & $\mathrm{cm}^{2}$ & 0.1550 \\
0.4536 & $\mathrm{lb}$ & $\mathrm{kg}$ & 2.2046 \\
1.6093 & $\mathrm{mph}$ & $\mathrm{km} \cdot \mathrm{h}^{-1}$ & 0.6214 \\
0.4732 & $\mathrm{pt}$ & $\mathrm{L}$ & 2.1134
\end{tabular}


through the opening. Pruning of 'Brightwell' plants was more severe than for 'Powderblue' plants because of the presence of massive canes on 'Brightwell' growing down the row or overarching in the middle. On some 'Brightwell' plants up to $50 \%$ of the canopy was removed. On most 'Powderblue' plants about $30 \%$ of the canopy was removed.

In June 2004 and Feb. 2005, 3-year-old 'FL 86-19' and 'Star' (3 to $4.5 \mathrm{ft}$ tall) southern highbush blueberry plants (Chambers Brothers Farm, Homerville, GA) were pruned. Pruning consisted of cutting out one to three upright canes growing in the center of the bush near the crown.

HAND HARVEST FOR YIELD ESTIMATION AND QUALITY EVALUATION. One day before machine harvesting, three or four plants in all four sections of pruned and unpruned rows of rabbiteye and southern highbush blueberries used in the experiment were strip harvested by hand, sorted into blue or green/red berries, and weighed. Because we conducted harvesting studies in grower fields, one-time harvesting of all the fruit was the only practical method of estimating yield.

MaCHINe HaRVESTING OF RABBITEYE AND SOUTHERN HIGHBUSH BLUEBERRIES. In June 2004, the 'Brightwell' plants were harvested once with the V45 harvester (Fig. 1). In June 2005, the 'Brightwell' and 'Powderblue' plants were harvested twice, 1 week apart with V45 and commercial sway harvesters (BEI). The V45 harvester was operated with the shaking frequency set at $6.25 \mathrm{~Hz}$ (cycles per second) and a ground speed of 1 mile/ $\mathrm{h}(\mathrm{mph})$. The BEI sway harvester was driven by the cooperating grower $(\mathrm{W}$. Hinson), who set the ground speed, displacement of shaking rods, and shake frequency to what he judged to be the best for high harvest efficiency. Before running the V45 harvester, the ground $1.5 \mathrm{ft}$ on either side of the plant row was raked. After the V45 harvester had passed, blue and green/red fruit in the raked area were counted and expressed as weight of fruit on ground (ground loss) per plant $\left(\approx 9 \mathrm{ft}^{2}\right)$. The detached fruit that landed on the catching surface (e.g., inclined padded surfaces and fish scales) rolled onto the conveyor system, which transported the fruit to the rear of the harvester, where the fruit was collected in a lug

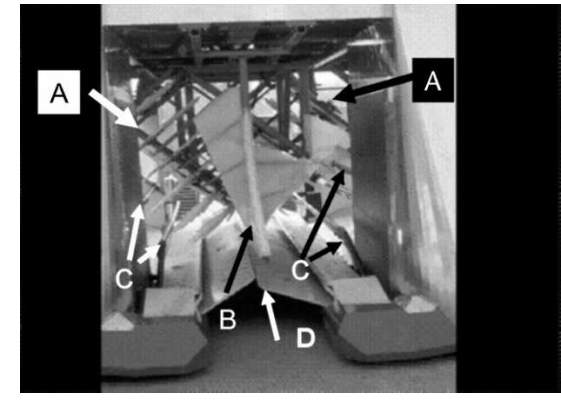

Fig. 1. Front view of the V45 blueberry harvester that was used to machine harvest rabbiteye and southern highbush blueberries. This harvester was manufactured by Blueberry Equipment, Inc. (BEI), South Haven, MI. The shaking apparatus

(A) comprises two angled, spiked-drum shaking units that are installed under a standard frame and the drive components of BEI's rotary harvester. Note the two drums are dynamically counterbalanced to each other and angled $45^{\circ}$ to the horizontal. A prow (B) consisting of a tube extending 36 inches $(91.4 \mathrm{~cm})$ in front of the harvester frame and a 6-inch-long $(15.2-\mathrm{cm})$ cone-shaped wedge starts at the leading edge of the prow and arches upward. Angled-positioning pipes (C) on each side of the harvester guide the canes that are diverted to left and right by the prow into the drum shakers (A). The $45^{\circ}$ angled catching surfaces and fish scales (D) are covered with "Soft NoBruze" cushioning (Connecticut Valley Corp., Shelton, CT) and direct the berries into BEI's standard horizontal bucket conveyors.

box. After the field tests were finished, lug boxes were weighed and blueberries from each sampling area were transferred to $1 / 2-p t$ containers for further evaluation. Before the second V45 harvest, six randomly selected clusters with green/red and blue fruit at the top, middle, and bottom third of 'Brightwell' and 'Powderblue' rabbiteye plants in each sampling area were tagged. Counts of green/red and blue fruit on the cluster were made before and after machine harvesting on 28 June 2005 to determine the amount of mature and immature fruit detached by the V45 blueberry harvester.

Pruned 'FL 86-19' southern highbush blueberry plants were machine harvested with the V45 on 27 and 29 Apr. 2005. Pruned 'Star' southern highbush blueberry plants were machine harvested with the V45 once on 3 May 2005. Shaking frequency was set at $6.25 \mathrm{~Hz}$ and ground speed was $1 \mathrm{mph}$. During each test, machine-detached fruit was conveyed to the rear of the harvester, where the fruit was collected in a lug box. Before machine harvest runs, all fruit $1-1 / 2 \mathrm{ft}$ on each side of the plant row and in the plant crown were removed, and a $\mathrm{l}-\mathrm{ft}-$ diameter ring was placed next to three plants in each sampling area. After the V45 harvester had passed, all blue and green/red fruit in the ring were counted and expressed as weight of fruit on the ground per plant. After the field tests were finished, lug boxes were weighed and blueberries from each sampling area were transferred into $1 / 2-p t$ clamshell containers for further evaluation.

We evaluated bloom (percent wax cover) and internal bruise damage for machine-harvested and handharvested fruit. Hand-harvested fruit samples for each sampling area were obtained from three to four plants in the adjacent rows on the day of V45 machine harvesting. Blue fruit was dropped into a l-gal plastic pail. A sample of fruit was poured out of the pail into lidded $1 / 2$-pt clamshell containers for further evaluation.

Fruit Quality evaluation. Fruit samples were evaluated for average berry weight of blue and green/ red berries, blue and green/red berries (percent), bloom (percent) on skin of blue fruit, fruit with stems attached (percent), fruit with cracked skin (percent), and internal bruising. Bloom (the fruit skin area where the wax coating is not disturbed) was visually determined on 50 fruit using reference photographs provided by MBG Marketing (Grand Junction, MI).

Hand- and machine-harvested fruit were evaluated for internal bruising using a method previously described (Brown et al., 1996; Peterson et al., 1997). Fruit were held at room temperature for $24 \mathrm{~h}$ and then 50 berries/sampling area were sliced through the equator with a razor blade. All the berries were sorted into four classes of bruising damage as follows: 1 , none or no bruise; 2 , slight or less than $25 \%$ of cut surface area had a bruise; 3 , moderate or between $25 \%$ and $50 \%$ of cut surface area had a bruise; and 4, severe or more than $50 \%$ of cut surface area had a bruise. The analysis examined the berries in each of the four classes of bruise damage.

EXPERIMENTAL DESIGN AND DATA ANALYSIS. In all cases, entire 170- to 
300 -ft-long rows were used for each treatment. In each cultivar, rows were divided into four sampling areas. For each cultivar tested, one row was selected for machine harvesting with the V45 and was pruned as described previously. Five to 10 contiguous plants in each area were machine harvested with the V45. Fruit on three or four plants at one end of each sampling area were stripped by hand $\mathrm{l} \mathrm{d}$ before machine harvesting for calculating yield. Determinations of the effect of pruning and harvest method for each cultivar on yield parameters and quality characteristics were analyzed. A one-way analysis of variance was performed on all appropriate data from four sampling areas using the Proc MIXED procedure of SAS (version 9.03; SAS Institute, Cary, NC). Calculated percentage values were transformed using arcsine of the square root of the percentage value. Treatment means were then separated using the PDIFF option. Statistical significance was expressed at the $P=0.05$ level. The chi-square test was used on classification data on the examination of individual berries for visible internal damage or on percent of cut surface with bruise damage (Steel and Torrie, 1960).

\section{Results and discussion}

EFFECT OF PRUNING ON RABBITEYE AND SOUTHERN HIGHBUSH BLUEBERRY YIELD. On 6- to 8-ft-tall rabbiteye blueberry, winter (dormant) pruning removed two to four large (>1.5 inch in diameter), stiff, upright canes in the center of the bush or growing down the row, constituting $50 \%$ or more of plant canopy of 'Brightwell' (Fig. 2). On 'Powderblue' rabbiteye blueberry, less severe cane pruning was necessary to open the middle. In both cultivars, the remaining canes were smaller, more flexible, or in a position in which they could be bent outward toward the row middle by the harvester. Yield of winter-pruned 'Powderblue' rabbiteye plants was $90 \%$ of unpruned plants $(11.7 \mathrm{lb} /$ plant vs. $13.0 \mathrm{lb} /$ plant), but 2005 yields of 'Brightwell' plants pruned heavily in Jan. 2004 and Feb. 2005 were only $57 \%$ and $46 \%$, respectively, of unpruned plants (Table 1). Annual removal of canes larger than $4 \mathrm{~cm}$ in diameter or removal of the oldest $20 \%$ of the canes is a recommended pruning practice for mature northern highbush blueberry plants (Gough, 1994; Siefker and Hancock, 1987). Although, Siefker and Hancock (1987) reported that on northern highbush blueberries in Michigan up to $40 \%$ of the largest canes could be removed without substantially reducing yields, Strik et al. (2003) showed that the "conventionally" pruned 'Bluecrop' and 'Berkeley' northern highbush blueberry plants in Oregon produced significantly less fruit compared with unpruned plants. The effect of pruning appeared to be related to cane age and number, but other factors (e.g., cultivar, plant age, and previous pruning history) may confound the results.
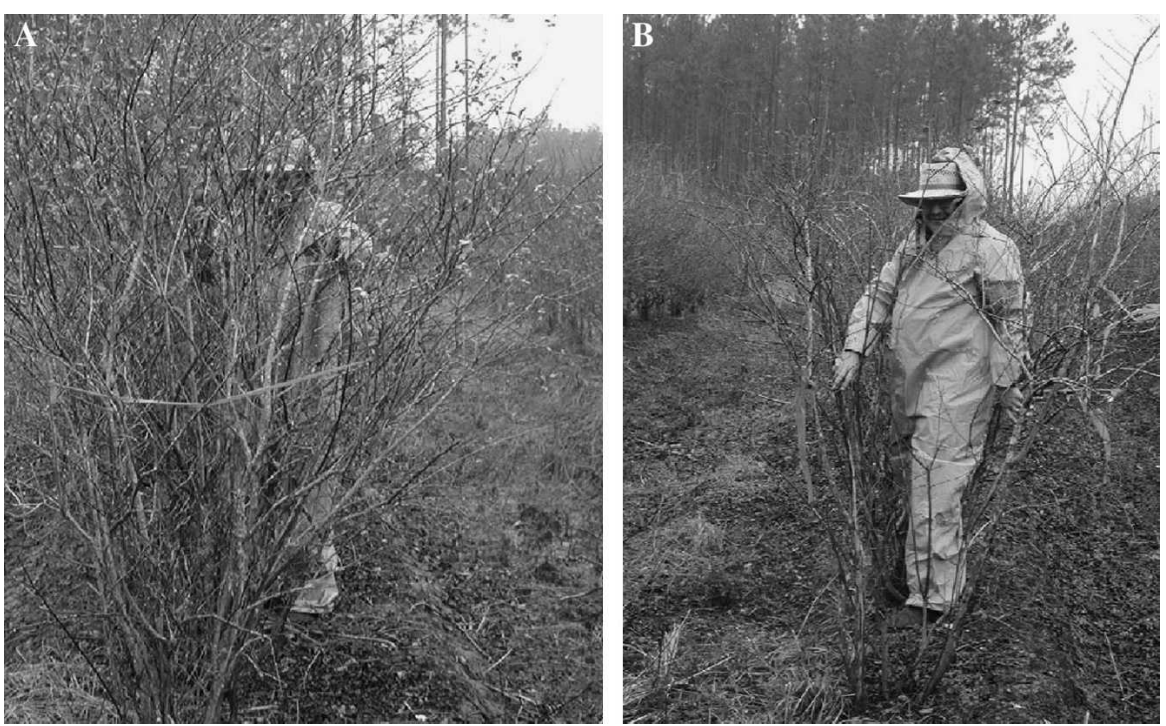

Fig. 2. Six-year-old 'Brightwell' rabbiteye blueberry plants used for mechanical harvesting with the $\mathrm{V} 45$ harvester. (A) A 'Brightwell' blueberry plant photographed before being pruned. Note the many upright canes in the middle of the plant. (B) A 'Brightwell' plant after it was pruned to cut out upright canes in the middle. Sufficient numbers of canes were pruned to create an opening wide enough for the pruner to walk through.

Table 1. Productivity of summer- and winter-pruned 'FL 86-19' and 'Star' southern highbush blueberry and winter-pruned rabbiteye blueberry.

\begin{tabular}{|c|c|c|c|c|}
\hline \multirow[b]{3}{*}{ Time of pruning } & \multicolumn{4}{|c|}{2005 yield $(\mathrm{lb} / \text { plant })^{\mathrm{z}}$} \\
\hline & \multicolumn{2}{|c|}{$\begin{array}{c}\text { Southern highbush } \\
\text { blueberry }\end{array}$} & \multicolumn{2}{|c|}{$\begin{array}{l}\text { Rabbiteye } \\
\text { blueberry }\end{array}$} \\
\hline & FL 86-19 & Star & Brightwell & Powderblue \\
\hline Not pruned & $3.5 \mathrm{a}^{\mathrm{y}}$ & $2.2 \mathrm{a}$ & $21.6 \mathrm{a}$ & $13.9 \mathrm{a}$ \\
\hline Jan. 2004 & $-^{x}$ & $-^{x}$ & $12.3 \mathrm{~b}$ & $-^{x}$ \\
\hline June 2004 & $2.6 \mathrm{~b}$ & $3.3 \mathrm{a}$ & $-^{x}$ & $-^{x}$ \\
\hline Feb. 2005 & $1.3 \mathrm{c}$ & $1.5 \mathrm{a}$ & $9.9 \mathrm{~b}$ & $11.7 \mathrm{a}$ \\
\hline
\end{tabular}

${ }^{\mathrm{z}} \mathrm{l} \mathrm{lb}=0.4536 \mathrm{~kg}$.

yean separation within columns using the PDIFF option of LSMeans statement in PROC MIXED (SAS version 9.03; SAS Institute, Cary, NC). Means in columns followed by the same letter are nonsignificant at $P=0.05$. xPlants were not pruned at this time.

Pruning consisted of cutting out several mature canes that were stiff and growing vertically, and overarching in the center to open the middle. Fruit on 'FL 86-19' and 'Star' southern highbush plants were strip harvested on 27 Apr. 2005 when some fruit had turned blue. Fruit on 'Brightwell' and 'Powderblue' rabbiteye blueberry plants were hand stripped $1 \mathrm{~d}$ before the first machine harvest on 22 June and 28 June 2005 respectively. 
canes must be removed for efficient operation of the V45 harvester because they can become entangled with the prow assembly at the front of the harvester and the shaking rods. If the V45 harvester encounters canes that cannot easily be bent into the shaking apparatus, then those canes can be broken off and it is possible that an entire plant could be pulled out of the ground, as observed by J. Vanerwegen of Homerville, GA.

On southern highbush blueberry plants ('FL 86-19' and 'Star'), one to three upright canes were removed during summer (June 2004) and winter (Feb. 2005) pruning of 3 - $\mathrm{ft}-$ to 5 -ft-tall plants (Fig. 3). By the following May, summer-pruned 'FL 86-19' plants had vigorous and flexible shoots in the center of the bush. Summer pruning had stimulated new cane development near the cuts. Significant fruit was produced on these 1-year-old shoots. Pruning out the upright canes near the ground improved the light entering the center of the bush and likely promoted flower bud formation later that summer. However, summer pruning of 'FL 86-19' in June 2004 and winter pruning in Feb. 2005 reduced fruit production in Spring 2005 by $25 \%$ and $62 \%$ compared with the unpruned plants respectively (Table 1). In 'Star', pruning did not affect plant yield (nonsignificant at $P=$ 0.05 ), although summer and winter pruning increased and decreased yield by $50 \%$ and $30 \%$ respectively.

MECHANICAL HARVESTING OF RABBITEYE AND SOUTHERN HIGHBUSH BLUEBERRY QUALITY. The preliminary mechanical harvesting study in June 2004 showed that both V45 and sway machines were not as selective as hand harvesting in detaching only the commercially mature, blue fruit. Nearly all the blue fruit was detached by hand harvesting. The 'Brightwell' fruit harvested with the V45 harvester was significantly superior to that harvested with the sway harvester, but was inferior to hand-harvested fruit (Table 2). Nearly all hand-harvested 'Brightwell' rabbiteye blueberry fruit was blue in color and marketable, and showed little internal bruising damage and good bloom. Compared with sway machine-harvested fruit, the V45-harvested fruit had more bloom intact, significantly less internal bruise damage and fruit with split skin, but more immature berries. Immature green and red fruit comprised $22 \%$ and $11 \%$ of fruit detached by the V45 and sway harvester respectively. A study in British Columbia compared several mechanical blueberry harvesters (e.g., BEI rotary, Korvan 9000 rotary, and Littau rotary) and found that the amount of green berries ranged from $1.1 \%$ to $7.0 \%$ of total yield (van Dalfsen and Gaye, 1999).

Fruit harvested by the sway harvester had less bloom, indicating that there were more fruit-to-fruit,
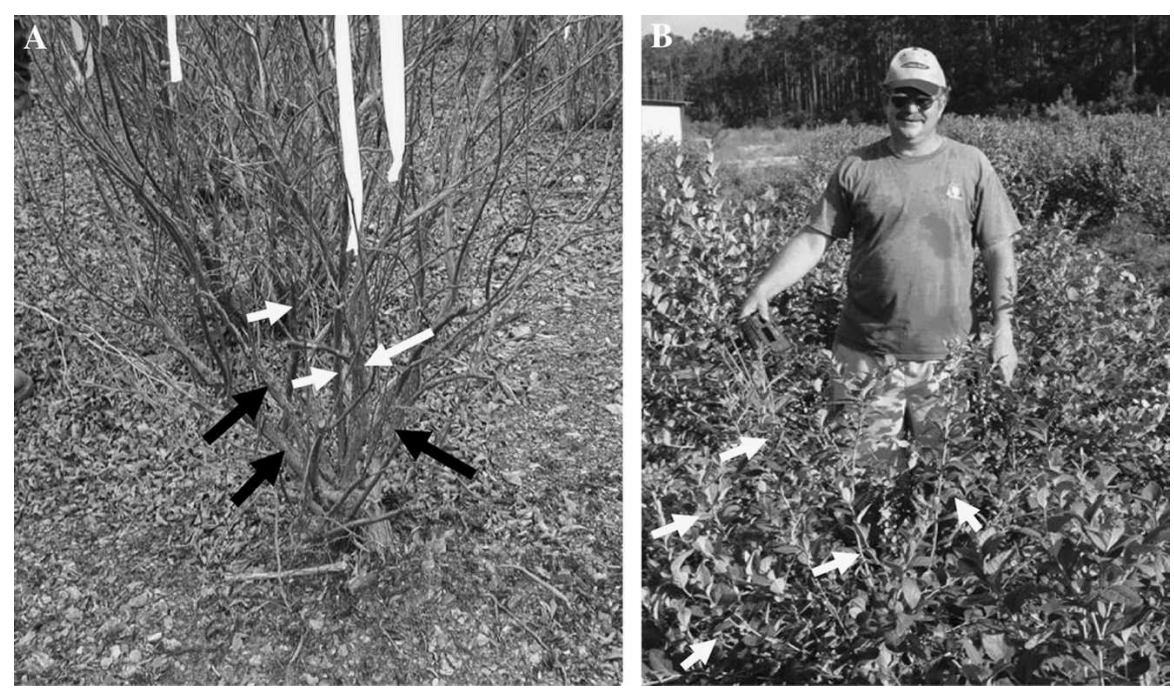

Fig. 3. Four-year-old 'FL 86-19' southern highbush blueberry plant. (A) Note there are about six mature primary scaffold branches (black and white arrows) on the trunk (photographed Feb. 2005). Pruning for V45 mechanical harvesting involved the cutting of upright scaffold branches (white arrows) in June 2004 and Feb. 2005. (B) An 'FL 86-19' southern highbush blueberry plant pruned in June 2004 for V45 machine harvesting in Spring 2005 (photograph taken 24 Apr. 2005). Note the absence of mature canes in the center of the plant and the amount of current-year cane growth (arrows).

Table 2. The effect of harvest methods on the fruit quality of 'Brightwell' rabbiteye blueberry in 2004 .

\begin{tabular}{|c|c|c|c|c|c|}
\hline \multirow[b]{2}{*}{$\begin{array}{l}\text { Harvest } \\
\text { method }\end{array}$} & \multirow[b]{2}{*}{$\begin{array}{c}\text { Bloom } \\
(\%)\end{array}$} & \multicolumn{3}{|c|}{ Categories of fruit removed } & \multirow[b]{2}{*}{$\begin{array}{l}\text { Internal rating } \\
\quad(0-4 \text { scale })^{\mathrm{y}}\end{array}$} \\
\hline & & $\begin{array}{c}\text { Blue fruit } \\
(\%)\end{array}$ & $\begin{array}{c}\text { Immature fruit } \\
(\%)\end{array}$ & $\begin{array}{c}\text { Split fruit } \\
(\%)\end{array}$ & \\
\hline Hand & $76 \mathrm{a}^{\mathrm{x}}$ & 97 a & $0 \mathrm{c}$ & 3 & 0.25 \\
\hline V45 machine & $61 \mathrm{~b}$ & $71 \mathrm{~b}$ & $22 \mathrm{a}$ & $7 \mathrm{~b}$ & $0.77 \mathrm{~b}$ \\
\hline Sway machine & $54 \mathrm{~b}$ & $65 \mathrm{~b}$ & $11 \mathrm{~b}$ & $24 \mathrm{a}$ & $2.13 \mathrm{a}$ \\
\hline
\end{tabular}

${ }^{2}$ Blue fruit was considered marketable.

${ }^{\mathrm{y}}$ Fruit were rated for internal bruise damage on a scale of 0 to 4 points where 0 point is no bruise indicated on cut surface, 1 point is $1 \%$ to $25 \%$ of cut surface showing bruise damage, 2 points is $25 \%$ to $50 \%$ of cut surface showing bruise damage, 3 points is $50 \%$ to $75 \%$ of cut surface showing bruise damage, and 4 points is $\geq 75 \%$ of cut surface showing bruise damage. The reported values are the mean of ratings from 50 berries.

${ }^{x}$ Mean separation within columns using the PDIFF option of LSMeans statement in PROC MIXED (SAS version 9.03; SAS Institute, Cary, NC). Means in columns followed by the same letter are nonsignificant at $P=0.05$. The sway harvester manufactured by Blueberry Equipment, Inc. (BEI, South Haven, MI) was used to machine harvest unpruned plants. The V45 harvester was used to machine harvest a row of plants pruned in Jan. 2004. Pruning of plants for V45 machine harvesting consisted of cutting out several mature canes that were stiff and growing vertically, and overarching in the center to open the middle. For comparison, hand-harvested fruit samples were taken from unpruned plants in a row next to the pruned row. All fruit samples were collected on 26 June 2004. Machine-harvested fruit samples were taken from fruit collection boxes at the back of the harvester. Harvested fruit were sorted into blue, immature, and split fruit after which blue fruit were poured into $1 / 2$-pt (0.24-L) containers and evaluated for bloom. Blue fruit were held for $24 \mathrm{~h}$ at room temperature and evaluated for internal bruise damage. 
fruit dropped from a height of 12 inches onto "Soft NoBruze" cushioning developed little internal bruise damage. Whether fruit was hand picked or harvested with the V45 blueberry harvester, the percentage of fruit with split skin was low (Table 2).

In 2005, the first hand and machine harvesting of 'Brightwell' rabbiteye blueberry plants occurred on 22 June when about $30 \%$ of the fruit had matured. The same plants were harvested the second time on 28 June. In 'Brightwell' blueberry, fruit surface quality was slightly less in V45 machine-harvested fruit compared with hand-harvested fruit (Table 3). The V45 harvester was not as effective as the sway harvester in selectively detaching mature, blue fruit. In 'Brightwell' blueberry, immature green and red fruit comprised 38\% of fruit detached by the V45 harvester, but only $19 \%$ and $1 \%$ or $2 \%$ in sway machine and hand-harvested fruit respectively (Table 3 ).

Internal quality of rabbiteye blueberry was affected by the harvesting method used to detach the fruit (Tables 3 and 4 ). In both first and second harvesting, internal quality of V45-harvested 'Brightwell' fruit was the same as that of hand-harvested fruit and was superior to fruit harvested by the sway harvester (Table 3 ). Only $27 \%$ and $17 \%$ of 'Brightwell' rabbiteye blueberry fruit detached by the sway harvester showed no or slight internal bruise damage respectively ( $<25 \%$ of cut surface with internal bruise), but $58 \%$ of fruit showed more than $50 \%$ of the cut surface with bruise (severe bruise). In 'Brightwell' rabbiteye blueberry, $56 \%$ to $84 \%$ of hand-harvested fruit were rated with no or slight bruising compared with
$59 \%$ and $79 \%$ for fruit harvested by the V45 harvester and only $8 \%$ and $26 \%$ of fruit detached by hand and the V45 harvester were rated severely bruised (Table 3). 'Powderblue' rabbiteye blueberry plants were harvested by hand and by the V45 blueberry harvester on 28 June, when about $50 \%$ of the fruit had matured. Although a lower percentage of V45harvested fruit in the "none" bruise category, $68 \%$ of V45-harvested fruit were rated none or slightly bruised compared with $85 \%$ for hand-harvested fruit. The V45 harvester detached fruit with good bloom, was selective in detaching blue fruit, and caused little internal bruise damage (Table 4). These results suggested that most hand- and V45-harvested fruit had an appearance and internal quality suitable for fresh market. Brown et al. (1996) indicated that blueberries with no or slight internal bruising can be cold stored as much as 6 weeks and still retain acceptable fresh-market quality.

We noted that the ground loss from harvesting pruned rabbiteye blueberries with the V45 harvester was less than $1 \%$ of the total fruit detached (data not presented). Low ground loss during harvest operation with the V45 harvester was attributed to its unique design features (Fig. 1). The prow and cone-shaped wedge at the front of the V45 harvester divides and bends the canes away from the crown. The shaking rods engage the bent canes from above, and detached fruit drops away from the plant base onto a slanted, padded catching surface. In contrast, the amount of fruit dropped (ground loss) during commercial mechanical harvesting can be high (Brown et al., 1983, Mainland,
1993; Peterson et al., 1997; Rohrbach and Mainland, 1988; van Dalfsen and Gaye, 1999). Fruit drops by commercial mechanical harvesters averaged $18 \%$ on highbush blueberries in British Columbia (van Dalfsen and Gaye, 1999). In North Carolina, southern highbush blueberry 'Reveille' and 'Bladen' were mechanically harvested for the fresh market with rotary and sway harvesters, but the ground loss was more than $20 \%$ (Rohrbach and Mainland, 1988). The ground around rabbiteye blueberry plants that is mechanically harvested with the BEI sway harvester or Advanced Blueberry Concepts' horizontal rotary harvester is typically littered with ripe and immature green/red fruit, which suggests that the fish scales are not forming tight seals around the canes at the plant base (F. Takeda, pers. obs.). Mainland (1993) recommended narrowing the base of the plant or growing cultivars with a narrow or upright growth habit to reduce ground loss when a vertical rotary or a sway mechanical harvesting system is used on southern highbush, so that the fish scales on the harvester can better seal around the base of the upright blueberry plants. If a gap forms between the canes and the fish scales of the harvester, then it is possible that some detached fruit can drop through the gap onto the ground.

The quality of rabbiteye blueberries harvested with the V45 was better than that harvested with a sway harvester, but not as good as handharvested fruit. The V45 did not selectively detach blue fruit from 'Brightwell' and 'Powderblue' plants as well as hand harvesting, and the V45 removed too many green and red fruit (Tables 2, 3, 4, and 5). On

Table 3. Fruit quality of hand- and machine-harvested 'Brightwell' rabbiteye blueberry in 2005.

\begin{tabular}{|c|c|c|c|c|c|c|c|c|c|c|c|c|}
\hline \multirow[b]{3}{*}{ Harvest method } & \multicolumn{6}{|c|}{ First harvest } & \multicolumn{6}{|c|}{ Second harvest } \\
\hline & \multirow{2}{*}{$\begin{array}{c}\text { Blue fruit } \\
(\%)\end{array}$} & \multirow[b]{2}{*}{ Bloom (\%) } & \multicolumn{4}{|c|}{ Internal bruising $(\%)^{\mathrm{y}}$} & \multirow{2}{*}{$\begin{array}{c}\text { Blue fruit } \\
(\%)\end{array}$} & \multirow{2}{*}{$\begin{array}{c}\text { Bloom } \\
(\%)\end{array}$} & \multicolumn{4}{|c|}{ Internal bruising (\%) } \\
\hline & & & None & $1-25$ & $26-50$ & $>\mathbf{5 0}$ & & & None & $1-25$ & $26-50$ & $>\mathbf{5 0}$ \\
\hline V45 machine & $62 c$ & $73 \mathrm{ab}$ & 34 & 25 & 15 & 26 & $62 c$ & $76 a$ & 57 & 22 & 10 & 11 \\
\hline Sway machine & $81 \mathrm{~b}$ & $68 \mathrm{~b}$ & 10 & 17 & 22 & 51 & $81 \mathrm{~b}$ & $46 \mathrm{~b}$ & 5 & 12 & 25 & 58 \\
\hline
\end{tabular}

${ }^{2}$ Mean separation using the PDIFF option of LSMeans statement in PROC MIXED (SAS version 9.03; SAS Institute, Cary, NC). Values within a column with the same letter are nonsignificant at $P=0.05$.

${ }^{y}$ Data for internal bruise damage from each harvest was subjected to a chi-square test. Chi-square calculated value for $3 \mathrm{df}$ and $P=0.05$ was 7.81 . Chi-square for damage was 11.5 .

Unpruned plants were harvested on 22 and 28 June 2005 by hand and with a sway harvester. The V45 mechanical harvester was used to harvest plants that were pruned in Jan. 2004. Pruning of plants for V45 machine harvesting consisted of cutting out several mature canes that were stiff and growing vertically, and overarching in the center to open the middle. The harvested fruit was sorted into blue and red/green fruit, and blue fruit were rated for bloom on the skin. Blue fruit were then held at room temperature for $24 \mathrm{~h}$ and rated for internal bruising. Fifty fruit from each sampling area were sliced through the equator with a razor blade. The berries were sorted into four classes of bruising damage based on the amount of bruise damage: 1 , none or no bruise indicated on the cut surface; 2 , slight or less than $25 \%$ of cut surface area had a bruise; 3 , moderate or between $25 \%$ and $50 \%$ of cut surface area had a bruise; and 4 , severe or more than $50 \%$ of cut surface area had a bruise. 
'Powderblue' plants, the V45 detached nearly all blue fruit in the top, middle, and bottom portions of the plant, but at the cost of detaching nearly $20 \%$ of immature fruit (Table $5)$. V45 harvest efficiency was less in 'Brightwell', especially in the bottom third of the plant canopy, where only $51 \%$ of blue fruit was detached (Table $5)$. Special pruning was needed to create a "V" for the harvester to pass a prow through the center of the bush, split the bush left and right, and engage the canes through the shaking mechanism. With the plants pruned to a $\mathrm{V}$ shape, damage to the canes by the V45 harvester was minimal (F. Takeda, pers. obs.).

In 'FL 86-10' and 'Star' southern highbush blueberry that were specially pruned for this study, we observed that the V45 harvester removed fruit without breaking canes. However, the quality of 'FL 86-19' southern highbush blueberry fruit picked by the V45 harvester was significantly worse than hand-harvested fruit (Tables 6 and 7). The V45 harvester was operated when only about $17 \%$ of 'FL 86-19' southern highbush fruit were ripe, as estimated by the crop load of $3.5 \mathrm{lb} /$ plant (Table 1 ), and only $0.6 \mathrm{lb} /$ plant of fruit was sufficiently mature to be hand harvested on 26 Apr. (Table 6). The first machine harvest occurred at the same time that the adjacent rows were being commercially hand harvested for fresh-market packing. The V45 removed too many green fruit. During the first harvest, blue fruit comprised only $66 \%$ and $50 \%$ of fruit detached by the V45 harvester in summer- and winter-pruned plants respectively. During the second harvest, blue fruit percentage slightly increased to $73 \%$ of berries detached by the V45 harvester (Table 6). During the first machine harvest, V45-harvested fruit had less intact bloom and a higher percentage of berries with its pedicle (stem) attached to the fruit than hand-harvested fruit (Table 6). One of the requirements for meeting the standards for "U.S. No. 1 Grade" is that the fruit be relatively free of attached stems (U.S. Department of Agriculture, 1997). The difference in internal fruit quality between hand harvesting of minimally pruned and V45 harvesting of winter-pruned plants was small (Table 7). All three treatments had more than $86 \%$ of fruit rated as having less than $25 \%$ of the interior cut surface showing bruise damage.

Table 4. Fruit quality of 'Powderblue' rabbiteye blueberry in 2005.

\begin{tabular}{lcccccr}
\hline \multirow{2}{*}{$\begin{array}{l}\text { Harvest } \\
\text { method }\end{array}$} & Bloom (\%) & Blue fruit (\%) & None & $\mathbf{1 - 2 5}$ & $\mathbf{2 6 - 5 0}$ & $>\mathbf{5 0}$ \\
\hline Hand & $83 \mathrm{a}^{\mathrm{z}}$ & $98 \mathrm{a}$ & 60 & 25 & 9 & 6 \\
V45 & $76 \mathrm{a}$ & $87 \mathrm{a}$ & 39 & 29 & 15 & 17 \\
\hline
\end{tabular}

${ }^{2}$ Mean separation using the PDIFF option of LSMeans statement in PROC MIXED (SAS version 9.03; SAS Institute, Cary, NC). Values within a column with the same letter are nonsignificant at $P \leq 0.05$.

'Data for internal bruise damage was subjected to a chi-square test. Chi-square calculated value for $3 \mathrm{df}$ and $P=0.05$ was 7.81 . Chi-square for damage was 11.5 .

The plants that were winter pruned in Feb. 2005 were machine harvested with the V45 harvester on 28 June 2005. Hand-harvested fruit samples were collected from unpruned plants in the adjacent row. The harvested fruit samples were sorted by visual color and rated for bloom on the skin. Blue fruit was rated for internal bruising after $24 \mathrm{~h}$. Fifty fruit from each sampling area were sliced through the equator with a razor blade. The berries were sorted into four classes of bruising damage based on the amount of bruise damage: 1 , none or no bruise indicated on the cut surface; 2 , slight or less than $25 \%$ of cut surface area had a bruise; 3 , moderate or between $25 \%$ and $50 \%$ of cut surface area had a bruise; and 4 , severe or more than $50 \%$ of cut surface area had a bruise.
The amount of mature fruit of 'Star' southern highbush blueberry detached by the V45 harvester was low $(<0.1 \mathrm{lb} /$ plant $)$; therefore, postharvest fruit quality evaluations were not performed. 'Star' southern highbush blueberry produces large fruit that develop in tight clusters. Early in the season, we noted that it was rather difficult to dislodge, even by hand, one or two blue fruit among several green fruit without disturbing the bloom. Generally, the first harvest of older highbush blueberry plants is done by hand to pick the large, early-ripening berries, and follow-up harvests are done with mechanical harvesters (Mainland, 1993; van Dalfsen and Gaye, 1999). This has the effect of opening up the clusters and improving removal of ripe berries in subsequent harvests.

In southern Georgia, the southern highbush blueberries are hand harvested at 2- to $3-\mathrm{d}$ intervals for up to 3 weeks, and rabbiteye blueberries are harvested either by hand or machine four or five times at 1 week apart. In this study, we machine harvested southern highbush and rabbiteye blueberries only once or twice, and the first machine harvest coincided with the first hand harvest.

The growing season in southern Georgia is long enough after harvest that new shoots of southern highbush blueberries that develop below the pruning cuts can grow as much as $2 \mathrm{ft}$ by late summer, and axillary buds become reproductive and set flower buds (Fig. 3). In rabbiteye blueberries the crop ripens much later (June and July) and there is not enough time for canes to regrow after harvest and set high numbers of flower buds on new canes. On more mature, large rabbiteye plants, severe pruning was needed

Table 5. Selective detachment of mature and immature fruits of 'Brightwell' and 'Powderblue' rabbiteye blueberries by the V45 blueberry harvester.

\begin{tabular}{|c|c|c|c|c|c|}
\hline Cultivar & $\begin{array}{c}\text { Cluster } \\
\text { location }\end{array}$ & $\begin{array}{c}\text { Fruit } \\
\text { (no./cluster) }\end{array}$ & $\begin{array}{c}\text { Blue fruit } \\
\text { (no./cluster) }\end{array}$ & $\begin{array}{c}\text { Blue fruit } \\
\text { detached by V45 } \\
\text { harvester (\%) }\end{array}$ & $\begin{array}{c}\text { Immature fruit } \\
\text { detached by V45 } \\
\text { harvester (\%) }\end{array}$ \\
\hline \multirow[t]{2}{*}{ Brightwell } & Top & $67 \pm 24$ & $24 \pm 9$ & $82 a^{z}$ & $17 \mathrm{a}$ \\
\hline & Bottom & $52 \pm 21$ & $10 \pm 5$ & $5 \mathrm{lb}$ & $20 \mathrm{a}$ \\
\hline \multirow[t]{2}{*}{ Powderblue } & Top & $28 \pm 12$ & $17 \pm 2$ & $95 \mathrm{a}$ & $17 \mathrm{a}$ \\
\hline & Middle & $26 \pm 11$ & $13 \pm 12$ & $90 \mathrm{a}$ & $16 \mathrm{a}$ \\
\hline
\end{tabular}

${ }^{2}$ Mean separation within each cultivar using the PDIFF option of LSMeans statement in PROC MIXED (SAS version 9.03; SAS Institute, Cary, NC). Values within a column for each cultivar with different letters are significantly different at $P=0.05$.

Mature (blue) and immature (red/green) fruit on six clusters located at top, middle, and bottom third of 'Brightwell' and 'Powderblue' rabbiteye blueberry plants were counted before and after a harvest pass by the V45 blueberry harvester. 
Table 6. Yield and external quality of hand- and V45-harvested 'FL 86-19' southern highbush blueberry on 26 Apr. and 28 Apr. 2005.

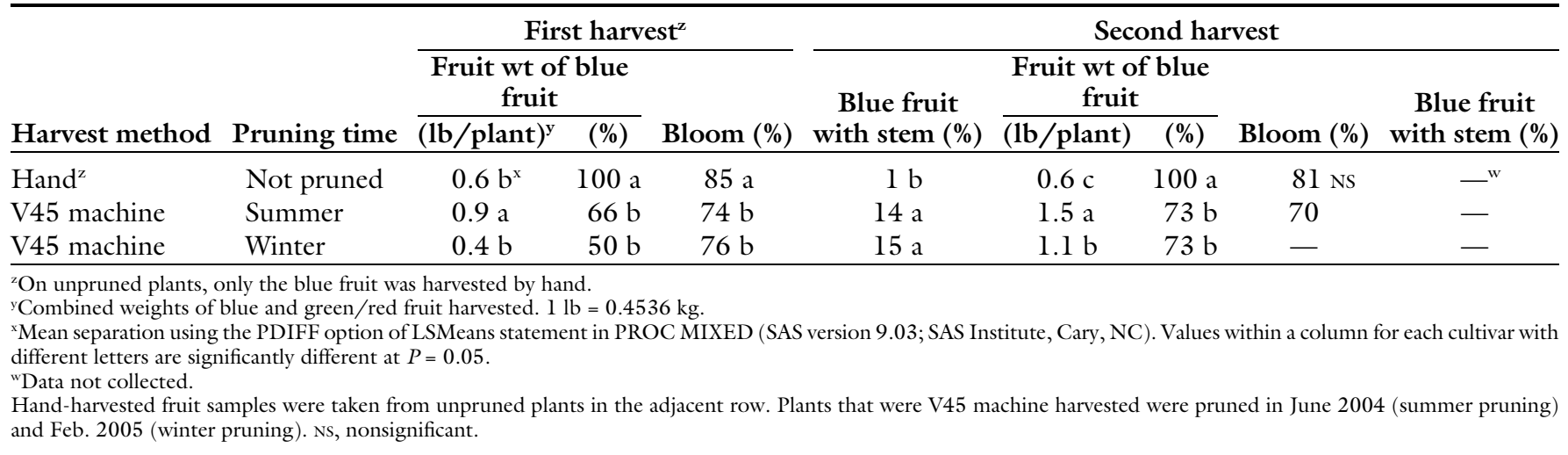

Table 7. The internal bruising in 'FL 86-19' southern highbush blueberry fruit harvested on 26 Apr. and 28 Apr. 2005 by hand and the V45 harvester.

\begin{tabular}{l}
\cline { 2 - 5 } \\
\cline { 2 - 6 }
\end{tabular}

to open the middle for the V45 harvester (Fig. 2). It may take more than three seasons for these bushes to become as productive as unpruned plants. At the time plants were strip harvested for this study, the weight of the blue fruit that was detached from pruned and unpruned plants was similar, but the total yield of pruned plants was reduced in 'FL 86-19' southern highbush and 'Brightwell' rabbiteye blueberries, but not in 'Star' southern highbush and 'Powderblue' rabbiteye blueberries. Strik et al. (2003) reported that pruned northern highbush blueberry plants produced berries that were larger and matured earlier compared with unpruned plants.

Growth habit and vigor of blueberry cultivars are important when considering machine harvesting with the V45. Northern highbush blueberries typically have a shrubby or spreading growth habit (Gough,
1994). In contrast, in most southern highbush blueberry plants and, to some extent, rabbiteyes, growth arises from a few trunks and then growth shifts to forking of stiff lateral branches (Fig. 3). The V45 angled double-drum shaker worked well in Michigan on 'Bluecrop' and 'Elliot' northern highbush blueberry plants, which have a spreading growth habit (Peterson and Brown, 1996; Peterson et al., 1997). Long, limber branches were more amenable to spreading sideways by the prow at the front of the harvester. If a planting is to be machine harvested with the V45, studies are needed to develop better pruning methods for promoting the growth of renewal canes from the crown. These alternative pruning and cane positioning techniques to shape the plant for harvesting by the V45 should begin when plants are still young so that extensive pruning as described in this study can be avoided. After plants are mature, annual cane thinning is suggested to remove more mature, large, stiff canes and to maintain a V-shaped opening in the middle (Figs. 2 and 3), rather than the current commercial practice of top and side hedging to contain plant size. Proper pruning practice to balance crop and plant vigor and to promote the growth of new canes from the base of the plant, and an analysis of cost and benefits of such pruning practice need to be developed.

\section{Conclusion}

A mechanical harvesting system for blueberries with high fresh-market-quality fruit is critical for the blueberry industry in the southeastern United States. The cost of hand harvesting will continue to increase. Also, blueberry production in southern Georgia is expected to double 
during the next 10 years (Strik and Yarborough, 2005). Expansion of production and markets for fresh blueberries and use of machines to harvest the fruit for that market segment requires that 1 ) the fruit harvested with mechanical harvesting systems have postharvest quality that is as good as hand-harvested fruit and meets the buyer's expectations; 2) mechanical harvesting systems must be improved so that postharvest handling and sorting operations are not excessive for separating fresh-marketquality fruit from green/red, bruised, stemmed, and other defective fruit; and 3) new cultural practices that increase the yield of high-quality fruit is needed. Our findings suggest that the V45 has the potential to harvest some rabbiteye blueberry cultivars mechanically with fruit quality approaching that of hand-harvested fruit. However, there are several disadvantages to using the V45 blueberry harvester for harvesting rabbiteye and southern highbush blueberries under current production practices. The V45 blueberry harvester detached more green fruit and stemmed fruit compared with hand-harvested fruit or fruit harvested by a sway machine. Also, the V45 harvester did not detach a high percentage of ripe berries on limbs near the ground, as noted in 'Brightwell' rabbiteye blueberry. The V45 blueberry harvester detached only a small portion of mature, blue fruit on the 'Star' plants. Also, the shaking apparatus on the V45 was too high for the shorter southern highbush plants because the lowest point of contact was about 24 in. off the ground.

We acknowledge the inherent limitation of this study. Mechanical fruit harvesting was not conducted over the entire season. Also, we operated the V45 harvester only at one ground speed and shaker frequency. We did not place machine-harvested fruit in long-term cold storage and perform fruit firmness tests. Whether the cost of additional production inputs as described here to make rabbiteye and southern highbush blueberries accessible to the V 45 blueberry harvester is warranted needs to be determined. Comprehensive mechanical harvesting studies are not common because of the complicated logistics of bringing together researchers, support personnel, equipment, and commercial growers in a coordinated effort.

More research is needed to develop an improved V45 blueberry mechanical harvesting system that will harvest more fresh-market-quality blueberries and will increase freshmarket pack-out, and fruit with potential for long-term cold storage. Production practices on rabbiteye blueberry must be modified before a V45 harvester can be used. It remains to be seen whether growers will adapt a new pruning practice on mature plants to open the center of the plants for efficient passage of the V45 blueberry harvester or consider using the V45 blueberry harvesting system over the conventional sway or rotary harvesting systems. If a grower is contemplating the V45 to harvest rabbiteye blueberry plants, it is suggested that pruning and cane positioning to create a $\mathrm{V}$-shaped canopy structure start soon after plant establishment, and that the grower develop practices to promote the growth of renewal canes and not allow canes to become too large in diameter. As blueberry production increases, it will become necessary to have fruit that can be stored longer. Some useful information was gained from this study. The results indicate that rabbiteye blueberries with high quality can be mechanically harvested with the V45 harvester. Positive findings of this study were that fruit harvested by the V 45 blueberry harvester had a better appearance and less internal damage compared with the sway harvester.

\section{Literature cited}

Brown, G.K., D.E. Marshall, B.R. Tennes, D.E. Booster, P. Chen, R.E. Garrett, M. O'Brien, H.E. Studer, R.A. Kepner, S.L. Hedden, C.E. Hood, D.H. Lenker, W.F. Millier, G.E. Rehkugler, D.L. Peterson, and L.N. Shaw. 1983. Status of harvest mechanization of horticultural crops. Paper no. 83-3, Amer. Soc. Agr. Eng., St. Joseph, MI.

Brown, G.K., N.L. Shulte, E.J. Timm, R.M. Beaudry, D.L. Peterson, J.F. Hancock, and F. Takeda. 1996. Estimates of mechanization effects on fresh blueberry quality. Appl. Eng. Agr. 12:21-26.

Fonsah, E.G., G. Krewer, K. Harrison, and M. Bruorton. 2004. Economic analysis of producing southern highbush blueberries in soil in Georgia. Univ. GA. AGECON 0493.18 Sept. 2006. <www.smallfruits. org/Blueberries/Production.htm>.
Fonsah, E.G., G. Krewer, K. Harrison, and D. Stanaland. 2004. Estimated cost and economics for rabbiteye blueberries in Georgia. Univ. GA. AGECON 0493. 20 Nov. 2006. <www.smallfruits.org/ Blueberries/Production.htm>.

Gough, R.E. 1994. The highbush blueberry and its management. Food Products Press, Binghamton, NY.

Krewer, G. and D.S. Nesmith. 2002. The Georgia blueberry industry: Its history, present state, and potential for development in the next decade. Acta Hort. 574:101-106.

Mainland, C.M. 1993. Blueberry production strategies. Acta Hort. 346:111-116.

Peterson, D.L. and G.K. Brown. 1996. Mechanical harvester for fresh market quality blueberries. Trans. Amer. Soc. Agr. Eng. 39:823-827.

Peterson, D.L., S.D. Wolford, E.J. Timm, and F. Takeda. 1997. Fresh market quality blueberry harvester. Trans. Amer. Soc. Agr. Eng. 40:535-540.

Rohrbach, R.P. and C.M. Mainland. 1988. Crown restrictions in blueberries reduce harvesting ground losses. Paper no. 88-1046. Amer. Soc. Agr. Eng., St. Joseph, MI.

Safley, C.D., W.O. Cline, and C.M. Mainland. 2005. Estimated costs of producing, harvesting, and marketing blueberries in the southeastern United States. Proc. 12th Biennial Southeast Blueberry Conference, Savannah, GA, p. 33-49.

Siefker, J.A. and J.F. Hancock. 1987. Pruning effects on productivity and vegetative growth in the highbush blueberry. HortScience 22:210-211.

Steel, R.G.D. and J.H. Torrie. 1960. Principles and procedures of statistics. McGraw-Hill, NY.

Strik, B., G. Butler, and E. Hellman. 2003. Pruning severity affects yield, berry weight, and hand harvest efficiency of highbush blueberry. HortScience 38:196-199.

Strik, B.C. and D. Yarborough. 2005. Blueberry production trends in North America, 1992 to 2003, and predictions for growth. HortTechnology 15:391398.

U.S. Department of Agriculture. 1997. United States standards for grades of blueberries. Agricultural Marketing Service, Fruits and Vegetable Division, Washington, DC.

van Dalfsen, K.B. and M.M. Gaye. 1999. Yield from hand and mechanical harvesting of highbush blueberries in British Columbia. Appl. Eng. Agr. 15:393-398. 